\title{
四川盆地多重生态系统服务景观指数评价与服务簇 识别
}

\author{
彭立, 邓 伟 ${ }^{*}$, 黄 佩, 刘 颖
}

四川师范大学地理与资源科学学院, 成都 610068

摘要: 明确多重生态系统服务与生态系统服务簇的空间格局对于维持区域生态安全格局与可持续发展至关重要。在评估四川 盆地 2015 年 6 种生态系统服务的基础上,计算了表征综合水平的多重生态系统服务景观指数; 进而分析了生态系统服务间权 衡与协同关系; 并基于 K-均值聚类法识别了研究区内生态系统服务簇的空间格局。研究结果表明:(1)研究区的多重生态系统 服务景观指数平均值达到 3.12 , 同时具有明显的空间分异性,整体上呈现出东南高西北低的空间分布格局,高值区主要分布于 川东平行岭谷区, 以林、草地为主的区域最高,城市建成区及其邻近地区最低。(2)6 种生态系统服务空间异质性显著,且不同 服务间协同与权衡关系并存,其中碳汇、生境质量和水土保持服务三者间的协同关系显著,碳汇、生境质量和水土保持服务与娱 乐和粮食供给服务间的权衡关系均较强; 产水服务与其他各项服务间的权衡与协同关系均较弱。(3) 四川盆地可划分为文化 旅游、食物供给、生态保育和多功能复合均衡型 4 种服务簇, 其空间布局与内部结构分异明显。文化旅游型服务簇面积最小,面 积占比为 $3.11 \%$, 主要分布于成都和重庆城镇及其周边地区, 其提供多重生态系统服务功能的能力最弱; 食物供给型服务簇主 要位于成都平原、浅丘及部分河谷区域,面积约占 $36.23 \%$; 生态保育型服务簇主要分布于盆周山地, 以林地为主导,其提供多重 生态系统服务功能的能力最强, 面积占比达 $22.61 \%$;多功能复合均衡型服务簇分布最广, 面积占比为 $38.04 \%$, 集中于川中、川 东丘陵及平行岭谷槽谷区域。采取差异化优化措施有利于整体提升四川盆地生态系统服务能力,维护区域生态安全格局。 关键词:生态系统服务簇;多重生态系统服务景观指数;权衡与协同;生态空间格局;四川盆地

\section{Evaluation of multiple ecosystem services landscape index and identification of ecosystem services bundles in Sichuan Basin}

PENG Li, DENG Wei* ${ }^{*}$, HUANG Pei, LIU Ying

College of Geography and Resources, Sichuan Normal University, Chengdu 610068, China

\begin{abstract}
Understanding the spatial pattern of multiple ecosystem services and ecosystem services bundles is crucial for maintaining the regional ecological security pattern and sustainable development. Based on the assessment of six ecosystem services in Sichuan Basin in 2015, this paper evaluated multiple ecosystem services landscape index (MESLI) representing the comprehensive level of ecosystem services, and analyzed the trade-offs and synergies between ecosystem services in the Sichuan Basin. Then, K-means clustering method was applied to explore the spatial pattern of ecosystem service bundles, which was helpful to reveal the local characteristics of the ecological pattern of the Sichuan Basin. The results demonstrated that: (1) the average value of multiple ecosystem services landscape index in Sichuan Basin reached 3.12, and it had obviously spatial differentiation. The overall ability of the study area to provide multiple ecosystem services at the same time was high. It presented a spatial distribution pattern that high in the southeast and low in the northwest. The high value areas
\end{abstract}

基金项目: 国家自然科学基金面上项目 (42071222); 国家自然科学基金重点项目 (41930651)

收稿日期: 2020-09-06; 网络出版日期:2021-07-23

* 通讯作者 Corresponding author.E-mail: dengwei@imde.ac.cn 
were mainly distributed in the parallel ridge valley area of eastern Sichuan, with the highest values area dominated by woodland and grassland, and the lowest values in the urban area and its adjacent areas. (2) Six ecosystem services in Sichuan Basin had significantly spatial heterogeneity. The synergy and trade-off relationships between ecosystem services existed simultaneously. Carbon storage, habitat quality, and soil conservation services showed a spatial distribution pattern of high around the basin and low in the central of the basin. Water yield service was higher in the southeast than in the northwest, and the highest in urban areas. High-value areas for food production service were concentrated in the Chengdu Plain and middle hilly area of Sichuan. High-value areas for entertainment service were mainly distributed in the main urban areas of Chengdu and Chongqing. There were significant synergies between carbon storage, habitat quality and soil conservation services, and prominent tradeoffs between the three services mentioned above and food production and entertainment services. The tradeoffs and synergies between water production service and other services were weak. (3) The Sichuan Basin could be divided into four service bundles: cultural tourism, food production, ecological conservation, and multi-functional balance with distinctly spatial distribution and internal structure. The cultural tourism bundle had the smallest area accounting for about $3.11 \%$ of the study area, which mainly distributed in the towns and surrounding areas of Chengdu and Chongqing, and its ability to provide multiple ecosystem services was the weakest. Food production service bundle accounted for about $36.23 \%$ of the study area which mainly located in the Chengdu Plain, shallow hills and some river valleys, with the cultivated land as the dominant type. The ecological conservation bundle was mainly distributed in the mountains around the basin, with forest land as the dominant type, which had the strongest ability to provide multiple ecosystem services. It covered $22.61 \%$ of the study area. Multi-functional balance bundle was the most widely distributed, accounting for about $38.04 \%$ of the study area. It mainly located in the valleys of the hills and parallel valleys in the central and eastern Sichuan, and was still dominated by cultivated land. Adopting differentiated optimization measures will be conducive to improving the overall ecosystem service level of the Sichuan Basin and maintaining the regional ecological security pattern.

Key Words : ecosystem services bundles; multiple ecosystem services landscape index; trade-offs and synergies; ecological spatial pattern; Sichuan Basin

生态系统服务是指人类直接或者间接从生态系统中获取的产品和服务, 可分为供给服务、调节服务、文化 服务和支持服务 4 大类型 ${ }^{[1-3]}$ 。生态系统服务在维系环境的动态平衡、保障人类的生产生活等方面起着不可 代替的作用 ${ }^{[4-5]}$ 。然而, 人口增长和经济发展增加了全球对生态系统供给服务的需求, 为满足这些需求而进 行的土地转换改变了全球生态系统,加剧了生态系统的压力, 同时其他服务 (如调节服务) 呈现减少趋势 ${ }^{[6]}$ 。 这对于充分发挥生态系统服务功能和维护区域生态安全格局具有抑制作用。定量评估生态系统服务供需能 力, 明确其空间格局特征及其转移和流动, 可有效表征区域生态安全格局 ${ }^{[7-8]}$ 。依据生态系统服务评价结果, 识别生态系统服务间的权衡与协同关系, 探索区域多重生态系统服务格局特征, 明确区域生态系统服务族的 空间分布与内部结构, 对维护区域生态安全格局至关重要。

国内外生态系统服务的研究已在其分类、评估、模拟与预测、集成应用等方面已经积累了大量的成 果 ${ }^{[9-10]}$ 。协调生态系统管理的多目标冲突和缓解生态服务间的权衡成为当前实现可持续发展的必然选 择 ${ }^{[11-12]}$ 。已有研究表明,生态系统服务间的权衡和协同作用在不同位置表现出空间多样性和异质性, 同时也

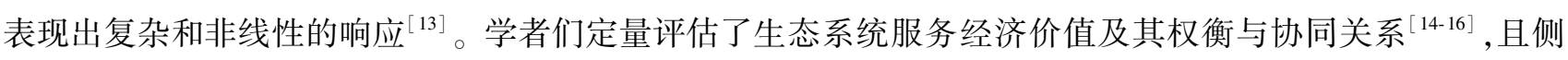
重于研究权衡与协同关系的形成机制, 尤其集中于研究土地利用变化、生态建设对生态系统服务权衡与协同 的影响 ${ }^{[17-18]}$ 。

多重生态系统服务景观指数 (Multiple Ecosystem Services Landscape Index, MESLI)代表了不同生态系统同 时提供多种服务的能力, 是识别多种生态系统服务的冷点和热点的一项综合性和有价值的环境指标 ${ }^{[13,19] 。}$ 
Rodriguez-Loinaz ${ }^{[20]}$ 等人在 2015 年首次提出该指标概念, 并运用该指数研究了巴斯克地区景观的多重生态系 统服务, 阐明了 MESLI 是衡量区域/地方景观多功能性的有效工具。生态系统服务簇 (Ecosystem Service Bundles，ESB) 是指一系列在空间和时间范围内生态系统服务的集合, 可用于定量分析多重生态系统服务在 空间上的集聚特征 ${ }^{[21]}$, 识别主导生态系统服务 ${ }^{[22]}$ 以及开展生态功能区划 ${ }^{[23]}$ 等。生态系统服务簇是一个较 新的概念, 由 Kareiva ${ }^{[24]}$ 等于 2007 年首次提出。国内外学者主要采用空间聚类的方法对生态系统服务簇进行

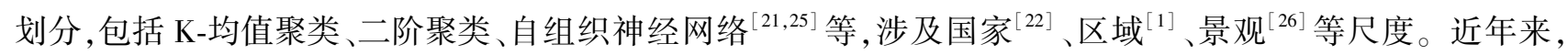
生态系统服务簇方面的研究也取得了一定的研究成果。例如, $\mathrm{Orsi}^{[27]}$ 等人计算了各生态系统服务, 评估了生 态系统服务之间的协同和权衡关系, 并确定了整个欧盟和成员国内部的生态系统服务簇空间格局。祁宁 ${ }^{[28]}$ 等人基于 K-均值聚类方法对东北地区进行了生态功能区划, 明确了生态系统服务的组成类型、协同与权衡关 系、形成机制和区域差异。

四川盆地位于中国西南部, 地处长江上游地区, 是长江上游地区生态屏障的重要组成部分, 对于维持整个 长江生态安全格局的具有重要作用。随着城镇化水平的推进, 生态环境保护压力日益加大。在快速城镇化和 自然生态保护的双重压力下, 迫切需要明确四川盆地生态系统服务间的权衡与协同关系以及服务簇的空间格 局, 对于维护区域生态安全具有重要意义。综上, 本文分析了四川盆地生态系统服务供给本底特征, 识别了生 态系统服务间权衡与协同关系, 明确了区域提供多种服务功能的能力, 进一步划分了生态系统服务簇, 并探讨 了每种生态系统服务簇空间格局与内部结构特征, 以期为研究区的土地管理、环境保护和生态建设等提供科 学依据。

\section{1 研究区与数据来源}

\section{1 研究区概况}

四川盆地 $\left(102^{\circ} 50^{\prime}-109^{\circ} 15^{\prime} \mathrm{E}, 27^{\circ} 39^{\prime}-32^{\circ} 45^{\prime} \mathrm{N}\right)$ 位于中国西南部, 地处高原大地形和东部平原的过渡 带, 西依青藏高原和横断山脉, 北近秦岭, 东接湘鄂西山地, 南连云贵高原, 覆盖面积 20 余万平方公里, 横跨四 川省中东部和重庆市大部分地区, 是中国第三大盆地。盆地内地形复杂多变, 自西向东可分为成都平原、川中 丘陵和川东平行岭谷 3 个地形区。气候以亚热带季风气候为主, 夏季高温多雨, 冬季温和少雨, 降水分布不 均, 年降水量达 800-1700 $\mathrm{mm}^{[29]}$, 年无霜期长达 280-350 d。盆地内成渝城市群城镇化、工业化进程推进迅 速, 是盆地内高速发展和经济发达的核心地区之一。随着经济的显著增长和城市的快速扩张, 截至 2015 年 底, 四川盆地国内生产总值 (GDP) 达到 6056 亿元, 人口总数达到 9885 万。本文主要借鉴前人的相关界 定 $^{[30-31]}$, 结合四川省和重庆市的数字高程模型 (DEM) 数据, 并考虑研究的完整性和数据的可获得性以县域为 基础单元划定了四川盆地的范围,共计 146 个区/县 (图 1)。

\section{2 数据来源}

本研究使用的数据主要包括遥感数据、地形数据、气候数据、社会经济数据等。统计数据来自《四川统计 年鉴 2016》和《重庆统计年鉴 2016》; 行政边界数据来自地理国情监测云平台 (http://www.dsac.cn/) ; DEM 数 据来源于 CIAT-CSI SRTM (http://srtm.csi.cgiar.org), 空间分辨率为 $90 \mathrm{~m} \times 90 \mathrm{~m}$; 植被净初级生产力 (NPP) 和 蒸散发 (ET) 遥感产品来自美国国家航空航天局 (NASA) 提供的地球观测数据 ( https://neo. sci. gsfc. nasa. gov/)。土壤数据来源于世界土壤数据库 (HWSD) ( http://webarchive. iiasa. ac. at/Research/LUC/ExternalWorld-soil-database), 空间分辨率为 $1 \mathrm{~km} \times 1 \mathrm{~km}$ 。气象数据包括降水、气温、日照时数等来源于中国气象科学 数据共享服务网 (http:/cdc. Cma. Gov.cn) ; 土地利用现状数据来自全球地表覆盖数据集 (http://data. ess. tsinghua.edu.cn/), 空间分辨率为 $30 \mathrm{~m} \times 30 \mathrm{~m}$; 人口空间分布数据来自于资源环境数据云平台 ( http: //www. resdc.cn), 空间分辨率为 $1 \mathrm{~km} \times 1 \mathrm{~km}$; 道路数据和酒店、学校等能反应人类活动的兴趣点 (Point of interest, POI) 数据基于 Python 爬虫技术从百度地图上获取。由于不同的数据源具有不同的空间分辨率, 最终评价结果均 统一到 $1 \mathrm{~km} \times 1 \mathrm{~km}$ 空间分辨率。 


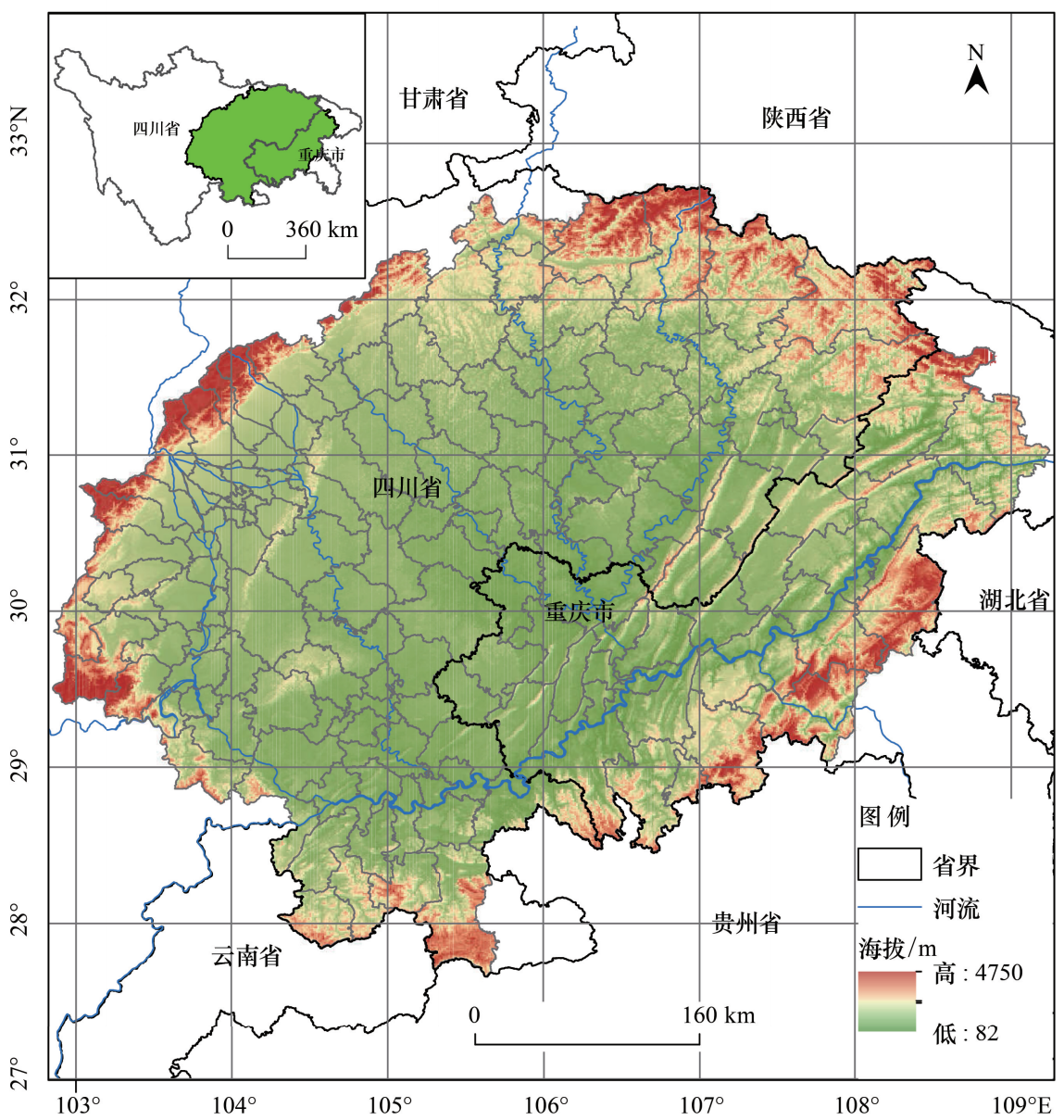

图 1 研究区地理位置

Fig.1 Location of the study area

\section{2 研究方法}

\section{1 生态系统服务}

InVEST 模型 (Integrated valuation of ecosystem services and trade-offs)也称为 “生态系统服务功能与权衡交 易综合评价模型”, 它整合了多种生物物理模型, 被广泛用于生态系统服务评价, 可有效揭示生态系统服务功 能空间分布与动态变化规律, 在生态系统服务功能评估和管理中具有重要意义 ${ }^{[32]}$ 。

考虑到不同生态系统对人类福祉的相对重要性、主要生态系统类别的代表性以及量化生态系统的数据可 用性,选择了 6 种关键生态系统服务: 碳汇、产水、粮食供给、生境质量、水土保持和娱乐服务, $\mathrm{z}$ 主要运用 InVEST 模型并结合粮食产量模型和娱乐服务评价模型对各类服务进行了定量评估。具体而言，以土地利用 类型为评估单元, 以土地利用/覆被类型的碳密度及面积计算研究区碳汇服务。每种土地利用类型的单位面 积生物量碳储量来源于前人的研究成果 ${ }^{[33-34]}$; 利用水分平衡原理 ${ }^{[35]}$ 计算各评价单元的产水量; 运用生境质量 评价模型 ${ }^{[36]}$ 计算生境质量服务; 利用植被净初级生产力和统计年鉴数据 (各行政单位的粮食产量) 估算研究 区域的粮食单产 ${ }^{[35]}$, 实现粮食供给服务空间化表达; 采用改进的土壤流失方程 ${ }^{[35]}$ 计算水土保持服务; 基于四 川盆地自然与社会经济状况, 从生态系统面积、娱乐机遇、人口聚集临近度和道路临近度四个维度, 评估了娱 乐服务 ${ }^{[37]}$ 。

\subsection{MESLI 计算}

多重生态系统服务景观指数 (Multiple Ecosystem Services Landscape Index, MESLI) 能有效识别区域同时提 
供多种生态系统系统服务的能力大小 ${ }^{[13,38]}$ 。不同的生态系统服务指数使用不同的指标, 其量纲之间存在着 显著差别。因此,首先应对各项指标进行标准化以去除量纲差异。MESLI 被定义为标准化生态系统服务指标 的总和, 以帮助识别和理解多种生态系统服务 ${ }^{[20]}$ 。其计算公式为:

$$
\text { MESLI }=\sum_{i=1}^{n} \frac{x_{i}-\min \left(x_{i}\right)}{\max \left(x_{i}\right)-\min \left(x_{i}\right)}
$$

式中, $i$ 为生态系统服务类型; $n$ 为生态系统服务种类数; $x_{i}$ 为第 $i$ 类生态系统服务观测值, $\max \left(x_{i}\right)$ 为第 $i$ 类 生态系统服务最大值, $\min \left(x_{i}\right)$ 为第 $i$ 类生态系统服务最小值。

\section{3 生态服务间的权衡协同}

尽管 MESLI 可表征整体的综合生态系统服务水平的高低,但无法明确各类生态系统服务间的相关关系。 然而,这对于维护区域的生态安全格局具有重要作用。因此,有必要进一步分析各类生态系统服务间的权衡 与协同关系。

空间自相关是一种多方向、多维度的自相关方法,全局 Moran's $I$ 指数可度量一个评价单元与其邻近单元 之间生态系统服务的空间聚集、离散以及空间自相关的程度 ${ }^{[39]}$ 。Moran's $I$ 指数值域范围为 $[-1,1]$, 若 Moran's $I>0$, 表明区域生态系统服务呈现空间正相关关系; 若 Moran's $I<0$, 表明区域生态系统服务呈现空间 负相关关系, 若 Moran's $I=0$, 表明区域生态系统服务呈现完全随机分布状态。其计算公式如下:

$$
I=\frac{n \sum_{a=1}^{n} \sum_{b=1}^{n} W_{a b}\left(x_{a}-\bar{x}\right)\left(x_{b}-\bar{x}\right)}{\left(\sum_{a=1}^{n} \sum_{b=1}^{n} W_{a b}\right) \sum_{a=1}^{n}\left(x_{a}-\bar{x}\right)^{2}}
$$

式中, $n$ 为评价单元总数, $x_{a} 、 x_{b}$ 分别表示评价单元 $a 、 b$ 不同的指标值, $W_{a b}$ 表示邻接单元 $a$ 与 $b$ 的空间权重 矩阵。

借助 RStudio 平台, 采用皮尔逊积矩 (Pearson) 相关系数法 ${ }^{[40]}$ 量化不同生态系统服务空间上的权衡与协 同关系。其计算公式如下:

$$
\rho_{X, Y}=\frac{N \sum_{i=1}^{N} x_{i} y_{i}-\sum_{i=1}^{N} x_{i} \sum_{i=1}^{N} y_{i}}{\sqrt{N \sum_{i=1}^{N} x_{i}{ }^{2}-\left(\sum_{i=1}^{N} x_{i}\right)^{2}} \sqrt{N \sum_{i=1}^{N} y_{i}{ }^{2}-\left(\sum_{i=1}^{N} y_{i}\right)^{2}}}
$$

式中, $X 、 Y$ 为两个变量, $N$ 为 变量取值的个数。当 $\rho_{X Y}=0$ 时, $X$ 和 $Y$ 不具有线性相关的关系; 当 $\rho_{X Y}>0$ 时, $X$ 和 $Y$ 具有协同关系; 当 $\rho_{X Y}<0, X$ 和 $Y$ 具有权衡关系; 当 $\rho_{X Y}$ 越接近 \pm 1 时,相关性越高。

为更加直观地表达不同生态系统服务间权衡与协同关系, 本研究将相关系数扩大了 100 倍, 以圆圈的大 小代表权衡与协同关系的高低,以不同颜色代表权衡与协同关系类型。

\subsection{K-均值聚类}

聚类分析通过衡量不同生态系统服务之间的相似性,把具有较高相似性的评价单元划分至同一生态系统 服务簇, 把具有较高相异度的单元划分为不同生态系统服务簇。为了得到较为稳定的聚类结果, 本文采用 K均值聚类分析方法。K-均值聚类是一种非监督学习的聚类方法, 具有运算速度快、计算量小的特点, 广泛应用 于分类问题中 ${ }^{[41-42]}$ 。计算公式如下:

$$
\begin{array}{rlrl}
d\left(x_{i}, x_{j}\right) & =\left[\sum_{r=1}^{p}\left|x_{i r}-x_{j r}\right|^{2}\right]^{\frac{1}{2}} & & \\
C(l) & =\arg \min _{1 \leqslant l \leqslant K} d\left(x_{i}, v_{l}\right) & & i=1,2, \cdots, N \\
v_{l} & =\arg \min _{v} \sum_{i \in C_{l}} d\left(x_{i}, v\right) & i=1,2, \cdots, N
\end{array}
$$

式中, $d\left(x_{i}, x_{j}\right)$ 代表该样本在聚类时计算的欧式距离; $x_{i}$ 为第 $i$ 个样本; $x_{i r}$ 为第 $i$ 个样本的第 $r$ 个特征参数; $C(l)$ 为 $l$ 类包含的样本集合; $v_{l}$ 为 $l$ 类的重心。重复上述步骤进行迭代,达到迭代终止条件时终止聚类过程。 
针对不同聚类数量的生态系统服务簇,其聚类结果存在显著差异。本研究采用斑块类型间的连通性来确 定 K-均值聚类的最佳生态系统服务簇数量。蔓延度指数 (Contagion Index, CONTAG) 和斑块结合度指数 (Patch Cohesion Index, COHESION) 指标是景观格局的重要指标, 常被用来量化斑块类型间的连通性。 CONTAG 描述的是景观中不同斑块类型的团聚程度或延展趋势 ${ }^{[43]}$ 。一般而言, 高蔓延度值说明景观中的某 种优势斑块类型形成了良好的连接性; 反之则表明景观是具有多种要素的密集格局,景观的破碎化程度较高。 COHESION 描述的是某一种斑块类型和周围相邻斑块类型的空间连接程度 ${ }^{[44]}$,其值越大, 表明斑块类型间的 连通性越强; 越小,表明连通性越弱。CONTAG 和 COHESION 在 Fragstats 软件中计算所得,不再赘述。

基于不同聚类两指数的计算结果,可确定生态系统 服务簇的最佳数量 (图 2)。随着聚类数量 (即生态系统 服务簇数量) 的增加, CONTAG 和 CHOESION 指数均在 聚类数为 4 时达到最大值。这表明, 当聚类数为 4 时, 研究区各斑块类型间的团聚程度以及连通性最强,最有 利于生态系统的稳定发展。因此,本研究选择 K-均值 算法聚类为 4 类时的生态系统服务簇作为最终分析 结果。

\section{3 结果分析}

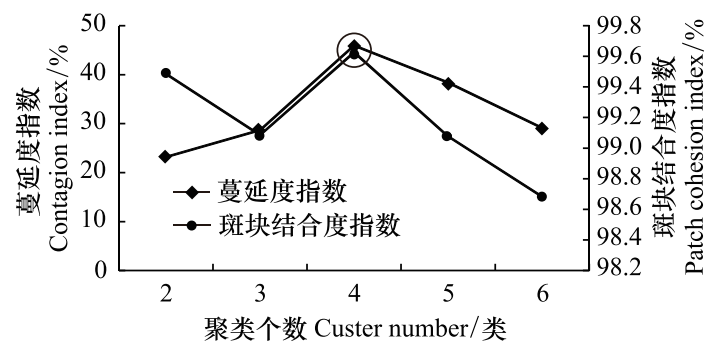

图 2 不同聚类数下景观指数对比

Fig.2 Landscape index under different cluster number

\section{1 生态系统服务及 MESLI 空间分布}

\subsection{1 生态系统服务评价}

由图 3 可知,就碳汇服务、生境质量服务和水土保持服务而言,整体均呈现出盆地四周高中部低的空间分 布规律,生态系统服务均值分别为 $16.28 \mathrm{t} / \mathrm{hm}^{2} 、 0.75 \mathrm{t} / \mathrm{hm}^{2}$ 和 $166.61 \mathrm{t} / \mathrm{hm}^{2}$ 。上述三种生态系统服务高值区主 要分布在盆地边缘以及东部的平行岭谷区,盆地内水田和旱地分布区服务值较低,其中城镇及其附近地区最 低。原因在于, 盆地边缘以及东部的平行岭谷区森林和草地分布广泛, 植被覆盖度较高, 人类活动强度相对较 小,因此具有较强的碳汇、土壤保持、生境质量服务的能力。就产水服务而言,东南部产水服务高于西北部,平 均值为 $70.35 \mathrm{~m}^{3} / \mathrm{km}^{2}$, 可能与降水量差异导致相关。其中, 城镇及其周边地区产水服务较高, 主要与城市热岛 效应显著、建设用地不透水面比例高、降水人渗低以及洪峰流量大等因素有关,这与申嘉澍 ${ }^{[37]}$ 等人的研究一 致。就粮食供给服务而言,其空间分布与碳汇、生境质量和水土保持等服务相反,呈现盆地中部高四周低分布 规律, 平均值为 $193.60 \mathrm{t} / \mathrm{km}^{2}$ 。粮食供给服务高值区集中分布于成都平原区和川中丘陵区,其中成都平原粮 食供给能力更强。就娱乐服务而言, 高值区主要分布于成都市和重庆市主城区,且有沿道路延伸的空间分布 规律, 平均娱乐服务指数为 0.28 。原因在于,该区域经济发达,人口分布相对集中,交通基础设施较为完善,通 达性高,娱乐服务水平以及可获得性较其他地区更高。

\subsubsection{MESLI 空间分布}

通过计算 MESLI 来比较四川盆地不同生态系统同时提供多种服务的能力 (图 4)。四川盆地 MESLI 具有 明显的空间分异性,整体上呈现出东南高西北低的空间分布格局,高值区主要分布在川东平行岭谷区,而成都 平原相对较低。就土地利用类型而言, 以林地和草地为主的区域 MESLI 最高,城市建成区及其邻近地区的 MESLI 值最低。原因在于, 盆地四周及川东平行岭谷区地势起伏大, 坡度较陡, 林地草地分布较广, 植被丰茂, 生物多样性丰富,受人类活动的影响相对较小,而成都平原区和川中丘陵区由于地势平坦,土壤肥沃, 交通便 利,耕地和建设用地占据主导,受人类活动影响大。因此,碳汇、生境质量、水土保持和产水等服务均整体上呈 现川东平行岭谷区及盆地四周高,成都平原和川中丘陵区低的空间分布特征。且由前文分析可知,研究区碳 汇、生境质量与水土保持服务之间存在极显著的协同关系,产水服务与其他服务之间也基本呈现协同关系, 权 衡关系极弱 (相关系数趋近于 0 ), 因此川东平行岭谷区及盆地四周地区提供多种生态系统服务的能力就越 

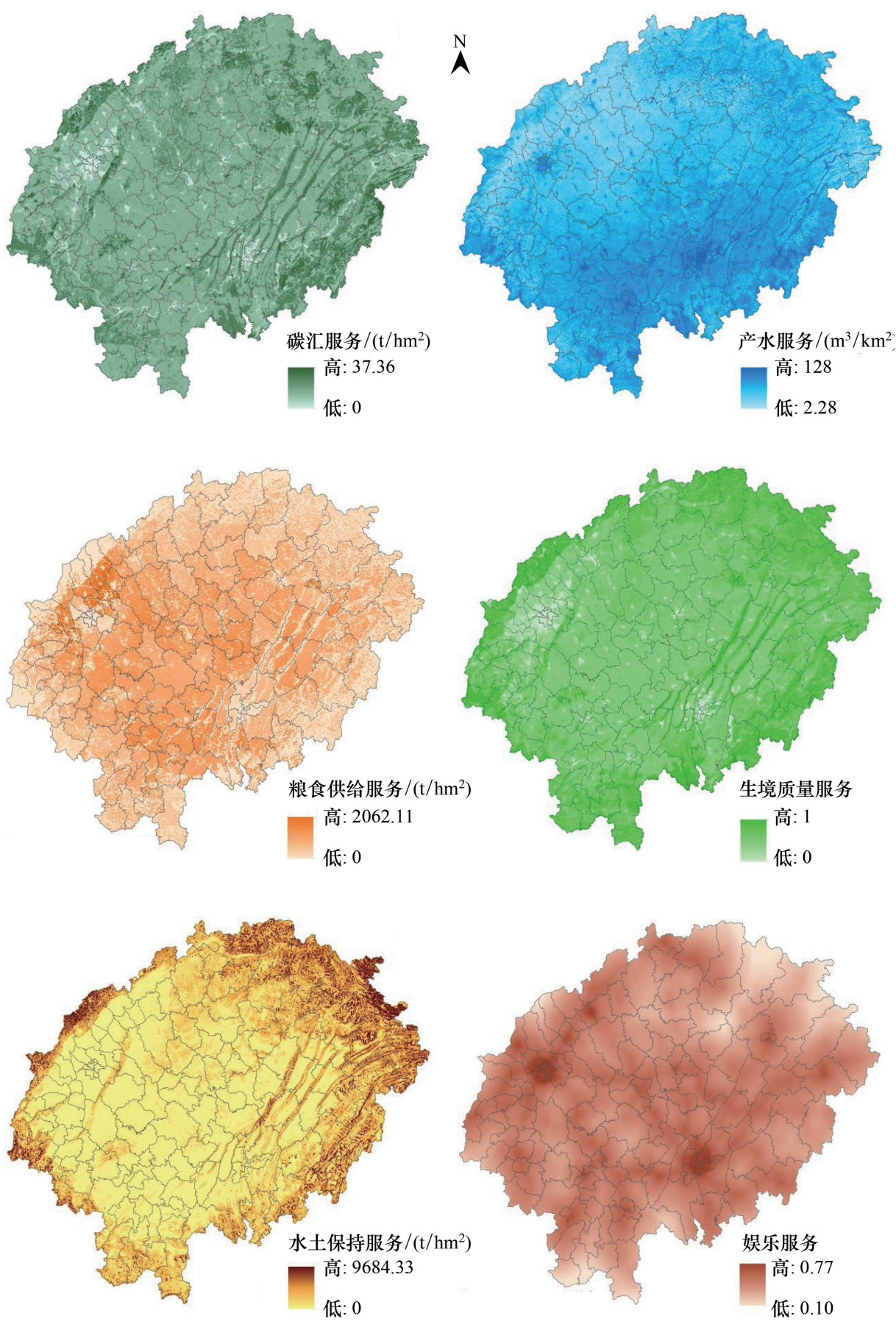

图 3 生态系统服务空间分布

Fig.3 Ecosystem services

强,这也就进一步可以解释林地和草地分布区 MESLI 指数高的原因。同理,城市建成区主要以单一的娱乐服 务为主, 因此同时提供多种服务的能力低,这也与我们的主观认知相符。整体来看, 四川盆地 MESLI 阈值范 围为 $[0.11,5.65]$, 平均 MESLI 指数为 3.12 。

3.2 生态系统服务间的权衡与协同关系

基于四川盆地的格网评价单元, 计算出 2015 年四川盆地生态生态系统全局 Moran's $I$ 指数 (表 1)。从 
表 1中明显看出, 四川盆地 6 种生态系统服务的全局 Moran's $I$ 指数均在 0.50 以上, 均大于 $0, P$ 值均小于 $0.01, Z$ 值均大于显著性水平 0.05 下的临界值 1.96 , 进 一步表明四川盆地 6 种生态系统服务都存在显著的空 间聚集特征 (正向空间自相关),这同时也说明了开展 空间聚类分析以识别生态系统服务簇的必要性。

由图 5 可知,在显著性水平 0.01 下,所有生态系统 服务都是显著相关的。水土保持服务与生境质量、碳汇 服务均呈现出较强的正向相关关系,具有相互增益的协 同关系, 其中与生境质量的协同关系最强, 相关系数达 0.48 ; 水土保持与娱乐服务、粮食供给服务间呈现出较 强的负相关关系, 相关系数分别为 -0.36 和 -0.33 , 具有 此消彼长的权衡关系; 水土保持与产水量之间的相关系 数为 -0.01 , 尽管呈现出权衡关系, 但这种权衡关系是非 常微弱的。此外,生境质量与碳汇服务、产水服务呈现 出协同关系,其中生境质量与碳汇服务之间的协同关系 最强,相关系数达 0.74 ; 生境质量与粮食生产和娱乐服

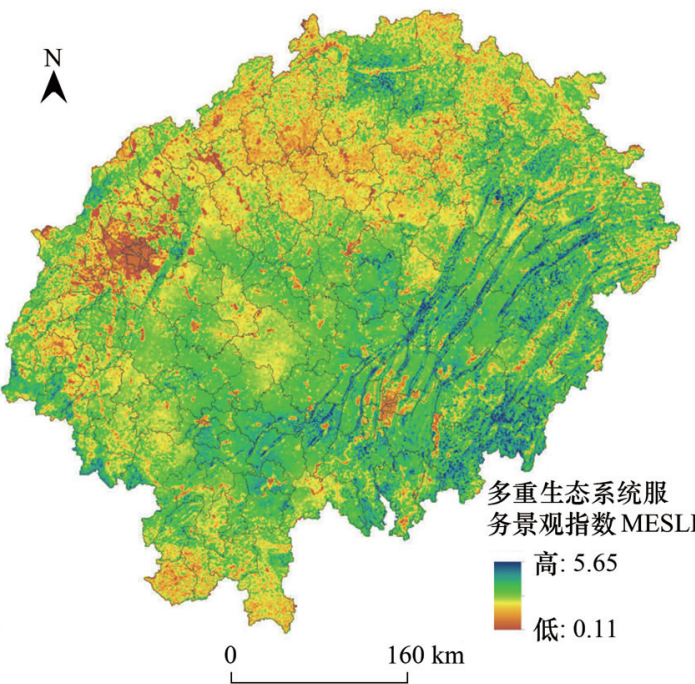

图 4 MESLI 空间分布

Fig.4 Spatial distribution of MESLI

MESLI : 多重生态系统服务景观指数, Multiple Ecosystem Services Landscape Index 务功能呈现出较强权衡关系, 相关系数分别为 -0.34 和

-0.33 。碳汇服务与娱乐服务、粮食供给服务之间仍然呈现较强的权衡关系,相关系数为 -0.22 。而娱乐服务 与粮食供给服务之间呈现出较强的协同关系,相关系数达 0.17 。产水服务与其他服务之间的权衡与协同关系 均较弱,其中产水服务与粮食供给服务之间的相关性最低,相关系数仅为 -0.03 。整体而言,水土保持、生境质 量、碳汇服务三者之间均存在显著的协同关系，三者与娱乐服务和粮食供给服务之间均存在显著的权衡关系。 原因可能在于, 高生境质量服务的区域,人类活动强度小,生物多样性丰富,植被丰茂,植被根系有助于土壤的 保持, 可有效抑制土壤沙化和水土流失, 同时, 植被光合作用强盛, 增加了植物的固碳能力 ${ }^{[28]}$ 。娱乐服务和粮 食供给服务高值区, 人类活动强度大, 人类在追求经济建设和粮食产量的同时,加大了对森林和草地生态系统 的破坏,水土保持、生境维持和固碳服务均很低。

表 1 各生态系统服务 Moran's I 指数

Table 1 The Moran's I value for various ecosystem services

\begin{tabular}{lcccrr}
\hline $\begin{array}{l}\text { 生态系统服务 } \\
\text { Ecosystem services }\end{array}$ & $\begin{array}{c}\text { 碳汇 } \\
\text { Carbon storage }\end{array}$ & $\begin{array}{c}\text { 产水 } \\
\text { Water yield }\end{array}$ & $\begin{array}{c}\text { 粮食供给 } \\
\text { Food production }\end{array}$ & $\begin{array}{c}\text { 生境质量 } \\
\text { Habitat quality }\end{array}$ & $\begin{array}{c}\text { 水土保持 } \\
\text { Soil conservation } \\
\text { Eoran's } I\end{array}$ \\
\hline Score & 0.67 & 0.75 & 0.51 & 0.72 & 0.75 \\
$P$ & 589.97 & 661.79 & 460.07 & 646.69 & 677.20 \\
\hline
\end{tabular}

\section{3 生态系统服务簇识别}

从各生态系统服务簇的玫瑰图 (图 6) 来看,第一类簇以娱乐服务和产水服务为主,且娱乐服务占据主导 地位,在该类服务簇中占比达 $46.96 \%$, 故将此类簇定义为文化旅游型服务簇。从生态系统服务簇的空间布局 来看 (图 7), 文化旅游型服务簇基本位于城镇区域,主要分布于成都和重庆主城区及都市连绵区、以及其他中 小城市建成区等地,其面积在所有服务簇中最小,仅占研究区总面积的 $3.11 \%$ 。第二类簇以粮食供给服务为 主导,粮食供给服务在该类服务簇中占比达 $24.20 \%$ 。且该类簇的粮食供给服务在四类簇中最大,约占四类簇 的粮食供给服务总和的 $48.66 \%$ 。因此,将此类族定义为食物供给型服务簇。从空间布局来看,食物供给型服 务簇主要位于成都平原、浅丘及部分河谷区域,其面积约为 7.42 万 $\mathrm{km}^{2}$,占研究区总面积的 $36.23 \%$ 。第三类 
簇以碳汇服务和生境质量服务为主, 二者在该服务簇中 的占比接近 50\%, 而产水服务其占比也达 $17.61 \%$ 因此 将此类簇定义为生态保育型服务簇。从空间分布来看, 生态保育型服务族主要分布于盆周山地, 包括大巴山、 龙门山脉以及川东平行岭谷等区域,约占四川盆地总面 积的 $22.61 \%$ 。在第四类簇中,除水土保持服务以外,其 他各项生态系统服务占比均在 $15 \%$ 以上, 且差异较小。 相对而言,该类生态系统服务簇内部结构较为均衡。因 此, 将此类服务簇定义为多功能复合均衡型服务簇。从 空间分布上而言,多功能复合均衡型服务簇主要位于川 中、川东丘陵及平行岭谷的槽谷区域, 其面积在四种服 务簇中为最大, 为 7.79 万 $\mathrm{km}^{2}$, 约占研究区总面积的 $38.04 \%$ 。

不同的生态系统服务簇受到土地使用类型的强烈 驱动, 并可由 MESLI 充分反映。分析各生态系统服务

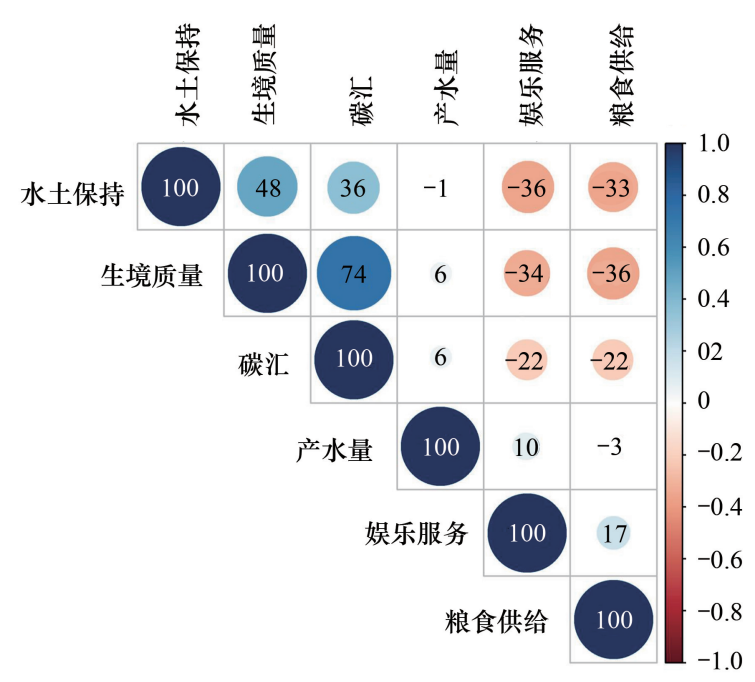

图 5 各生态系统服务相关性

Fig.5 Pearson correlations between pairs of ecosystem services 簇的 MESLI 均值, 可以进一步明确各生态系统服务簇 同时提供多种功能的能力。从各生态系统服务簇 MELSI 均值的三维柱状图来看 (图 8), 生态保育型>多功能 复合均衡型 $>$ 食物供给型 $>$ 文化旅游型服务簇, MELSI 均值分别为 3.56、3.24、2.81 和 1.90。整体而言,生态保 育型服务簇同时提供多种功能的能力最强, 文化旅游型服务簇最弱。这也与前文分析结果一致。

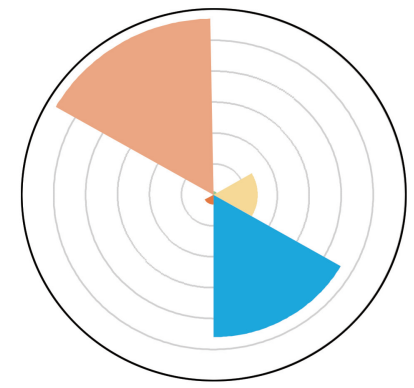

文化旅游型

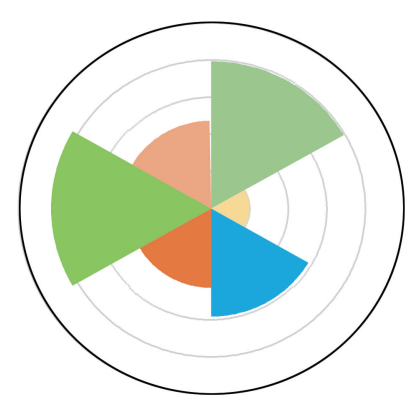

生态保育型

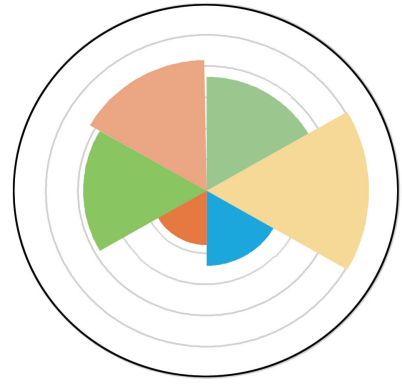

食物供给型

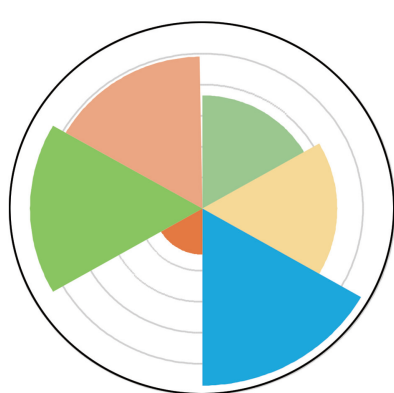

多功能复合均衡型

\section{碳汇服务 \\ 粮食供给服务}

产水服务

水土保持服务

—生境质量服务

娱乐服务

图 6 各生态系统服务簇功能结构

Fig.6 Functional structure of in each ecosystem service bundle

就生态系统服务簇内部的土地利用结构而言, 各服务簇差异较为明显。文化旅游型服务簇以建设用地占 据主导,其面积约 0.4 万 $\mathrm{km}^{2}$, 超过该服务簇总面积的 $60 \%$; 耕地次之, 面积占比约为 $29.19 \%$ 。食物供给型服 务簇以耕地为主导,耕地面积为 5.42 万 $\mathrm{km}^{2}$, 约占该服务簇总面积的 $73.07 \%$ 。生态保育型服务簇以林地为主 
导, 林地和草地面积最大, 约为 3.33 万 $\mathrm{km}^{2}$, 在该服务簇 总面积的占比超过 70\%。多功能复合均衡型服务簇内 部土地利用结构与食物供给型服务簇类似,仍以耕地为 主, 其他土地利用类型面积仅占 $26.93 \%$ 。尽管二者具 有相似土地利用结构, 且多功能复合均衡型服务簇中耕 地面积略高于食物供给型服务簇, 但需要明确的是, 食 物供给型服务簇主要位于成都平原, 由于地形、土壤肥 力、取水便利性、集约化水平等方面的优势,农作物产量 明显高于多功能复合均衡型服务簇所在区域。

\section{4 讨论}

维护区域的生态安全应充分考虑不同生态服务间 权衡关系与协同关系, 逐步提升生态系统服务所带来的 惠益。针对不同的生态系统服务簇可采取差异化的优 化措施以提升区域提供多种生态系统服务的能力。文 化旅游型服务簇区域应以协同关系为抓手,在发挥娱乐 服务以及产水服务优势的同时,加强区域的绿色生态规 划,如生态公园、公园城市的建设等,进一步降低城镇区

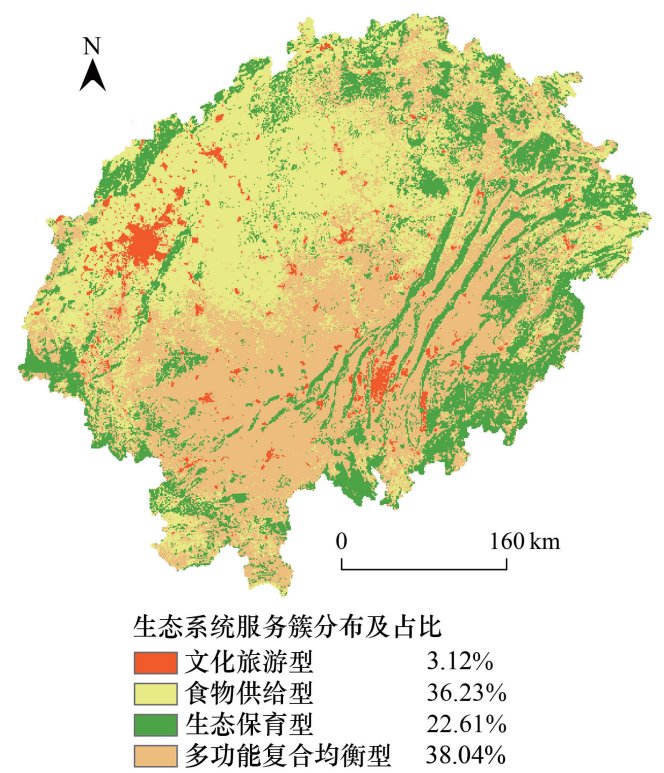

图 7 生态系统服务簇空间分布及占比

Fig.7 Spatial distribution and proportion of ecosystem service bundles 域娱乐服务与固碳、生境质量等服务间的权衡关系,促 进区域可持续发展。食物供给型服务簇区域首应保护耕地红线,促进土地集约利用,巩固粮食供给服务的主 导地位; 实施严格耕地占补平衡制度,特别要避免占用高质量农田; 减少不合理的耕作方式,注重水土保持和 生物多样性的维护,同时提升其固碳、生境支质量、水土保持等服务功能。生态保育型服务簇区域应当加强生 态集约化管理,严格实施退耕还林还草政策和天然林保护工程; 减少区域不合理的开发与建设活动,建立不同 形式的缓冲带, 如河岸带、防护林带等, 提升区域整体生态系统服务功能; 对于龙门山地以及东部平行岭谷区 域可因地制宜发展生态旅游 ${ }^{[45]}$, 逐步提升其文化旅游服务功能,促进区域碳汇生境支持、水土保持等服务与 文化娱乐服务协调发展, 实现经济社会发展和生态保护间的良性互动。多功能复合均衡型服务簇区域可采取 改变坡面微地形,增加植被覆盖度,并辅以护坡、护沟工程等措施提升水土保持及生境质量服务功能; 同时立 足于现阶段的农业发展条件,引进先进的农业科学技术,积极开展土地规模化经营,逐步提升区域的食物供给 服务功能。

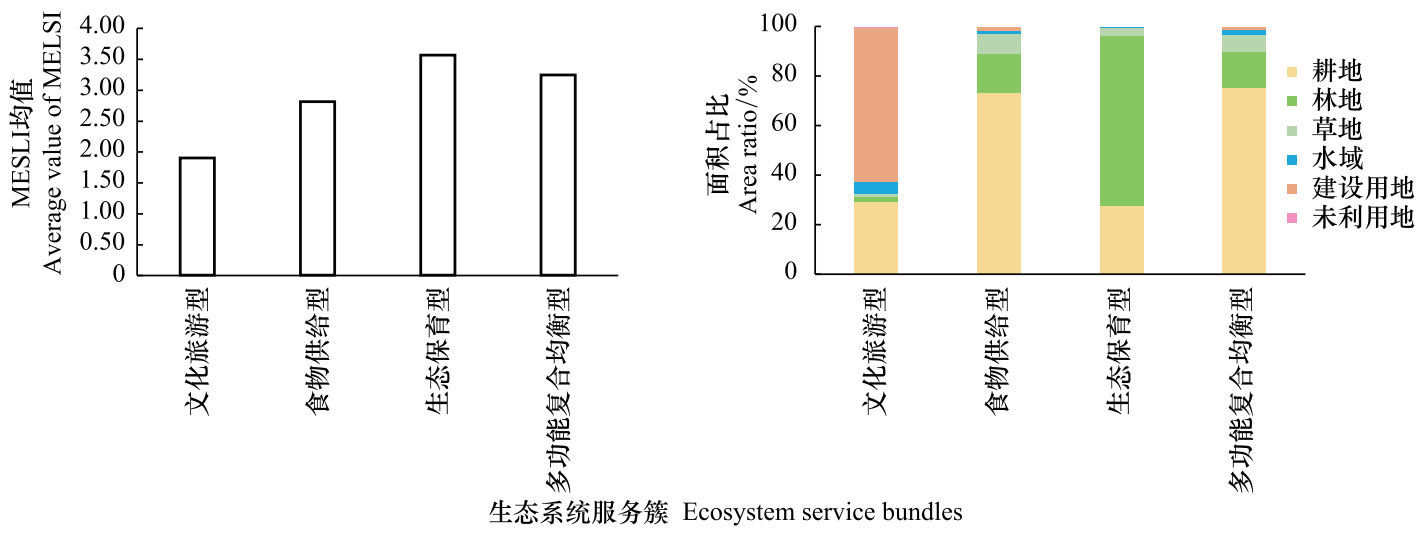

图 8 各生态系统服务簇 MELSI 均值与土地利用结构

Fig.8 MELSI average values and land use structures of each ecosystem service bundle 
在 K-均值聚类方法中, 聚类数并不能直接被计算, 需人为设定。因此, 聚类数的确定具有较强的主观性。 本文中为避免这一主观性, 依据景观生态学原理,采用了景观生态指标中的 CONTAG 和 COHESION 指数客观 划定了研究区的生态系统服务簇,并取得了良好的效果。此方法可为今后生态系统服务簇的研究提供一定的 借鉴意义。

MESLI 为直接刻画区域的多种生态系统服务功能提供了良好工具, 可广泛应用于多种生态系统服务的研 究。生态系统服务簇是多种生态系统服务的组合,生态系统服务簇的有效识别能够表征多种生态系统服务的 空间集聚特征和区域主导服务功能, 明确其内部空间结构特征可揭示不同生态系统服务的组合规律 ${ }^{[21]}$, 对于 开展生态系统服务管理具有重要指导意义。将 MESLI 与生态系统服务簇相结合, 探讨不同服务簇内部多种 生态系统功能布局、景观组分结构可为目前多层级国土空间规划的开展提供一种思路, 对于区域生态安全格 局的构建与促进区域可持续发展具有启示意义。

需指出的是, 本文仅对四川盆地截面上的生态系统服务的权衡与协同关系、多重服务功能以及生态服务 簇的内部空间格局开静态研究, 缺乏动态变化特征的揭示。在今后研究中, 长时间序列的生态系统服务及服 务簇时空分异规律有待进一步揭示和深人探讨。

\section{5 结论}

本文基于生态系统服务理论,分析了四川盆地生态系统服务的空间特征、权衡与协同关系以及区域提供 多重生态系统服务的能力, 基于 K-均值聚类法划分了生态系统服务簇类型, 明确了其空间分异性及内部结构 特征,并提出了相应的优化建议。主要得出以下结论:

(1) 四川盆地生态系统服务具有较强的空间异质性, 同时提供多种生态系统服的能力整体较高。碳汇、 生境质量和水土保持服务均呈现出盆地四周高中部低的空间分布规律; 产水服务东南部高于西北部, 且城镇 区域显著高于其他地区; 粮食供给服务高值区集中于成都平原区和川中丘陵区; 娱乐服务高值区主要分布于 成都市和重庆市主城区,且有沿道路延伸的空间分布规律。MESLI 具有明显的空间分异性,整体上呈现出东 南高西北低的空间分布格局, 区域 MESLI 均值达 3.12, 高值区主要分布在川东平行岭谷区, 而成都平原相对 较低; 以林地和草地为主的区域 MESLI 最高, 城市建成区及其邻近地区的 MESLI 值最低。

(2) 四川盆地各生态服务间协同与权衡关系并存。6 种生态系统服务都存在显著的空间聚集特征,所有 生态系统服务类型都是显著相关的。碳汇、生境质量和水土保持服务三者间协同关系十分显著, 三者与娱乐 服务和粮食供给服务之间均存在显著的权衡关系; 产水服务与其他服务之间的权衡与协同关系均较弱。

(3) 四川盆地可划分为文化旅游、食物供给、生态保育和多功能复合均衡型 4 种服务簇, 其空间布局与内 部结构分异明显。文化旅游型服务簇面积最小, 主要分布于成都和重庆主城区及都市连绵区、以及其他中小 城市建成区等地, 其提供多重生态系统服务功能的能力最弱, 应以协同关系为抓手, 加强区域的绿色生态规 划; 食物供给型服务簇主要位于成都平原、浅丘及部分河谷区域, 以耕地为主导, 应保护耕地红线, 促进土地集 约利用; 生态保育型服务簇主要分布于盆周山地, 包括大巴山、龙门山脉以及川东平行岭谷等区域, 以林地为 主导, 其提供多重生态系统服务功能的能力最强, 应实 施退耕还林还草政策, 减少区域不合理的开发与建设 活动; 多功能复合均衡型服务簇分布最广, 主要位于川中、川东丘陵及平行岭谷的槽谷区域,仍以耕地为主导, 应注重提升水土保持功能生境质量和食物供给功能。

\section{参考文献 (References) :}

[ 1 ] 冯兆, 彭建, 吴健生. 基于生态系统服务簇的深圳市生态系统服务时空演变轨迹研究. 生态学报, 2020, 40(8): 2545-2554.

[ 2 ] Costanza R, De Groot R, Braat L, Kubiszewski I, Fioramonti L, Sutton P, Farber B, Grasso M. Twenty years of ecosystem services: how far have we come and how far do we still need to go? Ecosystem Services, 2017, 28: 1- 16.

[ 3 ] 马琳, 刘浩, 彭建, 吴健生. 生态系统服务供给和需求研究进展. 地理学报, 2017, 72(7): 1277-1289.

[ 4 ] Gómez-Baggethun E, Barton D N. Classifying and valuing ecosystem services for urban planning. Ecological Economics, 2013, 86: 235-245. 
[ 5 ] 寿飞云, 李卓飞, 黄璐, 黄绍荣, 严力蛟. 基于生态系统服务供求评价的空间分异特征与生态格局划分一一以长三角城市群为例. 生态 学报, 2020, 40(9): 2813-2826.

[ 6 ] Vallet A, Locatelli B, Levrel H, Wunder S, Seppelt R, Scholes R J, Oszwald J. Relationships between ecosystem services: comparing methods for assessing tradeoffs and synergies. Ecological Economics, 2018, 150: 96-106.

[ 7 ] Li D L, Wu S Y, Liu L B, Liang Z, Li S C. Evaluating regional water security through a freshwater ecosystem service flow model: a case study in Beijing-Tianjian-Hebei region, China. Ecological Indicators, 2017, 81: 159-170.

[8] 卢慧婷, 严岩, 赵春黎, 吴钢. 雄安新区多尺度生态安全格局构建框架. 生态学报, 2020, 40(20) : 7105-7112.

[9] 邓楚雄, 刘俊宇, 李忠武, 肖海兵, 聂小东, 张宇婷, 周咪. 近 20 年国内外生态系统服务研究回顾与解析. 生态环境学报, 2019, 28 (10) : 2119-2128.

[10] 高江波. 喀斯特生态系统服务优化模拟与时空归因. 北京: 科学出版社, 2020: 1- 10 .

[11] Birkhofer K, Diehl E, Andersson J, Ekroos J, Früh-Müller A, Machnikowski F, Mader V L, Nilsson L, Sasaki K, Rundlöf M, Wolters V, Smith H G. Ecosystem services-current challenges and opportunities for ecological research. Frontiers in Ecology and Evolution, 2015, 2 : 87.

[12] Grêt-Regamey A, Sirén E, Brunner S H, Weibel B. Review of decision support tools to operationalize the ecosystem services concept. Ecosystem Services, 2017, 26: 306-315.

[13] Shen J S, Li S C, Liang Z, Liu L B, Li D L, Wu S Y. Exploring the heterogeneity and nonlinearity of trade-offs and synergies among ecosystem services bundles in the Beijing-Tianjin-Hebei urban agglomeration. Ecosystem Services, 2020, 43: 101103.

[14] 孙泽祥, 刘志锋, 何春阳, 邬建国. 中国快速城市化干燥地区的生态系统服务权衡关系多尺度分析一一以呼包鄂榆地区为例. 生态学报, 2016, 36(15): 4881-4891.

[15] Gong J, Liu D Q, Zhang J X, Xie Y C, Cao E J, Li H Y. Tradeoffs/synergies of multiple ecosystem services based on land use simulation in a mountain-basin area, western China. Ecological Indicators, 2019, 99: 283-293.

［16］高江波, 左丽媛, 王欢. 喀斯特峰丛洼地生态系统服务空间权衡度及其分异特征. 生态学报, 2019, 39(21) : 7829-7839.

[17] Li B J, Chen D X, Wu S H, Zhou S L, Wang T, Chen H. Spatio-temporal assessment of urbanization impacts on ecosystem services: case study of Nanjing City, China. Ecological Indicators, 2016, 71: 416-427.

[18] 王鹏涛, 张立伟, 李英杰, 焦否, 王浩, 延军平, 吕一河, 傅伯杰. 汉江上游生态系统服务权衡与协同关系时空特征. 地理学报, 2017,72 (11) : 2064-2078

[19] Manning P, van der Plas F, Soliveres S, Allan E, Maestre F T, Mace G, Whittingham M J, Fischer M. Redefining ecosystem multifunctionality. Nature Ecology \& Evolution, 2018, 2(3): 427-436.

[20] Rodríguez-Loinaz G, Alday J G, Onaindia M. Multiple ecosystem services landscape index : a tool for multifunctional landscapes conservation. Journal of Environmental Management, 2015, 147: 152- 163.

[21] 李慧蕾, 彭建, 胡熠娜, 武文欢. 基于生态系统服务簇的内蒙古自治区生态功能分区. 应用生态学报, 2017, 28(8): 2657-2666.

[22] Raudsepp-Hearne C, Peterson G D, Bennett E M. Ecosystem service bundles for analyzing tradeoffs in diverse landscapes. Proceedings of the National Academy of Sciences of the United States of America, 2010, 107(11) : 5242-5247.

[23] 吴健生, 钟晓红, 彭建, 秦维. 基于生态系统服务簇的小尺度区域生态用地功能分类一一以重庆两江新区为例. 生态学报, 2015, 35 (11) : 3808-3816.

[24] Kareiva P, Watts S, McDonald R, Boucher T. Domesticated nature: Shaping landscapes and ecosystems for human welfare. Science, 2007,316 (5833) : 1866-1869.

[25] Liu Y X, Li T, Zhao W W, Wang S, Fu B J. Landscape functional zoning at a county level based on ecosystem services bundle: methods comparison and management indication. Journal of Environmental Management, 2019, 249: 109315.

[26] Crouzat E, Mouchet M, Turkelboom F, Byczek C, Meersmans J, Berger F, Verkerk P J, Lavorel S. Assessing bundles of ecosystem services from regional to landscape scale: insights from the French Alps. Journal of Applied Ecology, 2015, 52(5) : 1145-1155.

[27] Orsi F, Ciolli M, Primmer E, Varumo L, Geneletti D. Mapping hotspots and bundles of forest ecosystem services across the European Union. Land Use Policy, 2020, 99: 104840.

[28] 祁宁, 赵君, 杨延征, 苟睿坤, 陈佳琦, 赵鹏祥, 李卫忠. 基于服务簇的东北地区生态系统服务权衡与协同. 生态学报, 2020, 40(9)： 2827-2837.

[29] 于影, 周筠珺, 李倩, 姜琪, 邱威腾, 吴笛, 崔雪锋. 基于 CMIP5 模式对四川盆地湿季降水与极端降水的研究. 高原气象, 2020, 39(1)： 68-79.

[30］汤宇否, 杨复沫, 詹宇. 四川盆地 $\mathrm{PM}_{2.5}$ 与 $\mathrm{PM}_{10}$ 高分辨率时空分布及关联分析. 中国环境科学, 2019, 39(12): 4950-4958.

[31] 汪可可, 康平, 周明卫, 张小玲, 陈军辉, 向卫国. 四川盆地臭氧浓度空间分异及驱动因子研究. 中国环境科学, 2020, 40(6)： 2361-2370. 
[32] 谢余初, 巩杰, 张素欣, 马学成, 胡宝清. 基于遥感和 InVEST 模型的白龙江流域景观生物多样性时空格局研究. 地理科学, 2018, 38 (6) : 979-986.

[33] 李屹峰, 罗跃初, 刘纲, 欧阳志云, 郑华. 土地利用变化对生态系统服务功能的影响一一密云水库流域为例. 生态学报, 2013, 33(3): 726-736.

[34] 胡海清, 罗碧珍, 魏书精, 魏书威, 孙龙, 罗斯生, 马洪斌. 小兴安岭 7 种典型林型林分生物量碳密度与固碳能力. 植物生态学报, 2015, $39(2)$ : 140-158.

[35] 赵雪雁, 杜昱璇, 李花, 王伟军. 黄河中游城镇化与生态系统服务耦合关系的时空变化. 自然资源学报, 2021, 36(1): 131-147.

[36］张静静, 朱文博, 朱连奇, 李艳红. 伏牛山地区森林生态系统服务权衡/协同效应多尺度分析. 地理学报, 2020, 75(5)：975-988.

[37] 申嘉澍, 梁泽, 刘来保, 李德龙, 张亚朋, 李双成. 雄安新区生态系统服务簇权衡与协同. 地理研究, 2020, 39(1): 79-91.

[38] 彭建, 吕慧玲, 刘炎序, 陈昕, 胡晓旭. 国内外多功能景观研究进展与展望. 地球科学进展, 2015, 30(4): 465-476.

[39] 张晗, 赵小敏, 欧阳真程, 郭熙, 匡丽花, 李伟峰. 基于空间自相关的耕地质量空间差异特征及耕地保护分区一一江西省上高县为例. 水土保持研究, 2018, 25(1):304-312.

[40] 余梓航, 徐嘉桦, 姚志玉, 梁伟典. 基于皮尔逊相关系数的网购大数据分析一以天猫佰润居旗舰店交易记录为例. 韩山师范学院学报, 2020, 41(3): 16-22.

[41] 汪欢欢. 基于 K-均值聚类与贝叶斯判别的区域创新极培育能力评价一一我国 30 个省市自治区为例. 工业技术经济，2019，38(5)： 136- 142 .

[42] Li Y C, Xie Y C. A new urban typology model adapting data mining analytics to examine dominant trajectories of neighborhood change: a case of Metro Detroit. Annals of the American Association of Geographers, 2018, 108(5) : 1313-1337.

[43] 蔡青. 基于景观生态学的城市空间格局演变规律分析与生态安全格局构建 [D ]. 长沙: 湖南大学, 2012.

[44] 刘晓君, 李占斌, 李鹏, 张铁钢, 徐国策, 高海东. 基于土地利用/覆被变化的流域景观格局与水沙响应关系研究. 生态学报, 2016, 36 (18) : 5691-5700.

[45］李晓琴. 龙门山地区山地旅游资源特征及开发模式探讨. 地理与地理信息科学, 2010, 26(2) : 107-110. 